\title{
Mechanisms of protonic surface transport in porous oxides - example of YSZ
}

Sindre Østby Stub, Einar Vøllestad and Truls Norby*

Centre for Materials Science and Nanotechnology, Department of Chemistry, University of Oslo, FERMiO, Gaustadalléen 21, NO-0349 Oslo, Norway

* Corresponding author: truls.norby@kjemi.uio.no

Keywords: conductivity, protonic; isotope effect; porous oxide; emf; proton transport; water adsorption; YSZ

\begin{abstract}
The electrical properties and the charge carrier mechanism of porous $8 \mathrm{~mol} \%$ yttria-stabilized zirconia (8YSZ) ceramic samples have been investigated over wide ranges of relative humidity $(\mathrm{RH})$ and temperature $\left(25-400{ }^{\circ} \mathrm{C}\right)$. The presence of humidity introduces protonic surface conduction, and porous YSZ shows pure protonic conduction below $\sim 150{ }^{\circ} \mathrm{C}$. H/D isotope effect studies combined with transport number measurements reveal a change in transport mechanism from structural diffusion (Grotthuss type) to vehicular transport when the relative humidity exceeds $\sim 60 \% \mathrm{RH}$, coinciding with a change in the adsorbed water layer from an "ice-like" to a "water-like" structure. Similarly, the activation energy for proton transport decreases from 0.43 $\mathrm{eV}$ to $0.28 \mathrm{eV}$ when the relative humidity increases from $20 \% \mathrm{RH}$ to $84 \% \mathrm{RH}$, reflecting changes in the enthalpies of formation and migration of charged species with increasing water layer thickness.
\end{abstract}

\section{Introduction}

Proton conduction in adsorbed water in porous nanocrystalline oxides is attracting attention for use in various electrochemical devices at near-ambient temperatures. ${ }^{1-2}$ As an example, the conductivity of a porous thin film of anatase is reported to be as high as $3.8 \cdot 10^{-2} \mathrm{Scm}^{-1}$ at $80{ }^{\circ} \mathrm{C}$ and $81 \%$ relative humidity $(\mathrm{RH}) .{ }^{3}$ Ceramic $\mathrm{Y}$-stabilized $\mathrm{ZrO}_{2}(\mathrm{YSZ})$, known as a pure oxide ion conductor under a broad range of conditions, remarkably has shown protonic conduction at low temperatures. $^{1-2,4-8}$ Other ceramic oxides such as $\mathrm{CeO}_{2}{ }^{9-13}$ and $\mathrm{TiO}_{2}{ }^{3,}$, ${ }^{14-15} \mathrm{SiO}_{2}$ gels and glasses, ${ }^{16-20}$ and functionalized porous $\mathrm{SiO}_{2}{ }^{21-24}$ also show similar behaviour. Moreover, particle hydrates, investigated in the early 1990' $\mathrm{s}^{25-27}$, and humidity sensors based on the conductivity of porous oxides $^{28-29}$ are other examples of protonic conduction in porous oxides known under other names. Altogether, we may refer to all of this as surface protonics. 
Although low temperature protonic conduction thus is well known, it was for a while debated whether transport in the "new" class of nanocrystalline $\mathrm{ZrO}_{2}$ and $\mathrm{CeO}_{2}$ oxides occurred along the grain boundaries or in the adsorbed water layers of pore surfaces. It is now however established that the protonic conduction in porous nanocrystalline oxides at low temperatures primarily takes place in the chemisorbed and physisorbed water layers on the pore walls..$^{2,8,15,30-31}$ Moreover, we have shown in a recent paper that the protonic surface conduction comprises two series connected processes which together compose a parallel rail to the bulk and grain boundary conduction of oxide ions. ${ }^{31}$ These are intra-grain transport - along the single grain's surface and inter-grain transport - conduction across the intersection between two adjacent grains, where the latter is highly resistive at low relative humidity. However, types of charge carriers, conduction paths, and the energetics of the charge carriers involved in surface protonic conductivity are still unclear.

A recent study suggested that the protonic transport mechanism in adsorbed water changes from Grotthuss-type diffusion (also known as structural diffusion) at high temperatures and low water content to vehicular transport $\left(\mathrm{H}_{3} \mathrm{O}^{+}\right)$at lower temperatures and high water content, ${ }^{8}$ based on a diminished H/D isotope effect below $50{ }^{\circ} \mathrm{C}$. Several other studies discussed the protonic transport mechanism based on activation energies. For instance, the conductivities of porous thin films of $\mathrm{TiO}_{2}$ and $\mathrm{SiO}_{2}$ are shown to obey Arrhenius behaviour under fixed relative humidity, 3, 22 where the activation energies decrease with increasing RH. Based on activation energies in the range of 0.1-0.4 eV, the authors draw the conclusion that proton migration is dominated by a Grotthuss mechanism. However, considering that similar activation energies are reported for Nafion and other polymeric proton conductors, and strong acids such as $\mathrm{HCl}$ where vehicle type diffusion dominates, ${ }^{32-35}$ one cannot unambiguously conclude on the transport mechanism based on activation energies alone.

A more direct way to distinguish the protonic transport mechanism is through transport number determination by measuring the electro-motive force $(e m f)$ under a water vapour gradient. ${ }^{36}$ There are no reports on transport number measurements for porous oxides, but the technique has been used as direct evidence of vehicle-type transport of protons in polymeric membranes, ${ }^{37-38}$ which is generally accepted as the predominant protonic transport mechanism in these materials at high RH.

The present contribution is part of a dedicated effort to investigate the protonic charge carrier mechanism in porous nanocrystalline oxides as function of temperature and relative humidity. We have for this purpose examined the H/D isotope effect of porous nanocrystalline YSZ as function of temperature under wet conditions and as function of $\mathrm{RH}$ at $25^{\circ} \mathrm{C}$. The type of charge carrier and mechanism is investigated further by transport number measurements at $30^{\circ} \mathrm{C}$ under wet conditions. Moreover, activation energies for the protonic transport are determined as 
function of temperature at different distinct levels of RH. Based on variations in transport number, isotope effect and activation energy with temperature and relative humidity we discuss the charge carrier mechanism of protons in adsorbed water in porous oxides. Finally, a mathematical expression relating surface conduction to simple physical properties is derived to shed light on the different material specific properties which govern proton conduction on oxide surfaces.

\section{Water structure on oxide surfaces}

The protonic surface conductivity is reported to increase drastically with increasing relative humidity, 32, 31,39 and consequently with the properties of the adsorbed water layers. We will therefore briefly introduce the properties of the water layers on oxides as a function of temperature and humidity.

The amount of water adsorbed on an oxide surface is described by Langmuir and BET theory, ${ }^{40-}$ ${ }^{41}$ and depends on the thermodynamics of the water adsorption reaction. Figure 1 shows qualitatively the structure of the adsorbed water layer. The chemisorbed water layer comprises a layer consisting of terminated and multi-coordinated hydroxyls, and molecular adsorbed water with hierarchically hydrogen bonded layer. ${ }^{8}$ The hydroxyls are stable up to temperatures higher than $600{ }^{\circ} \mathrm{C}$ and the hydrogen bonded layer to temperatures around $200{ }^{\circ} \mathrm{C}$ at $p_{\mathrm{H}_{2} \mathrm{O}}=0.025 \mathrm{~atm} .{ }^{8}$

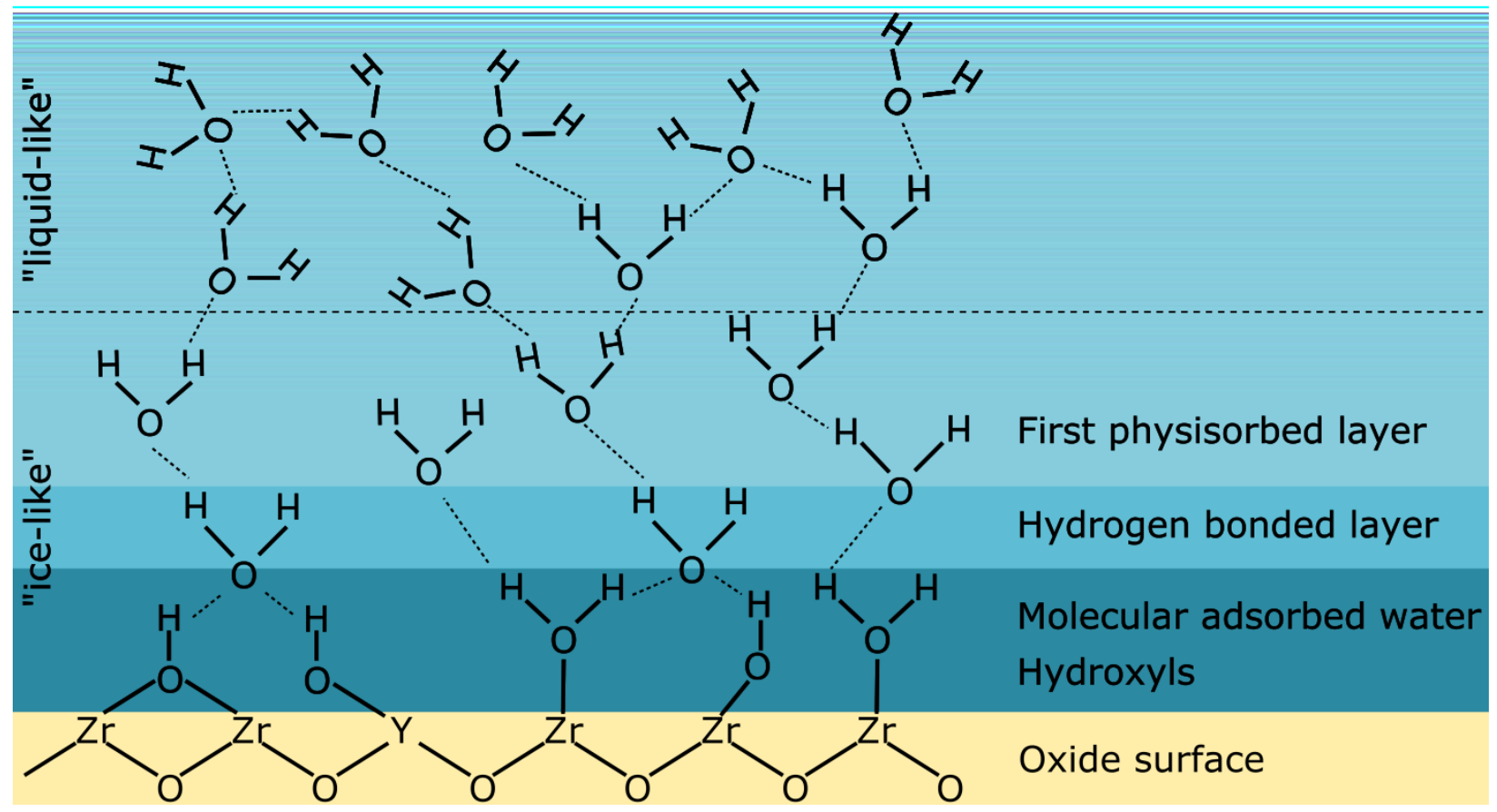

Figure 1. Qualitative sketch of the water layer struture on a YSZ surface. The hydroxyls and the hydrogen bonded layer together comprise what we refer to as chemisorbed water. 
The amount of physisorbed water in the sample is determined by the relative humidity. At $30 \%$ $\mathrm{RH}$, the water layer consists of three monolayers; two chemisorbed layers and one monolayer of physisorbed water that in combination display an "ice-like" structure. ${ }^{42}$ From $30-60 \%$ RH, the second physisorbed layer adsorbs and comprises a transitional structure between "ice-like" and "water-like" structure. Above $60 \%$ RH the water molecules are more loosely bonded and behave more similar to free water. Multilayers form above $80 \% \mathrm{RH}$. Thus, it is reasonable to expect that the protonic transport in the surface water layer changes significantly with increasing amount of adsorbed water on the surface.

\section{Transport number measurements}

In general, a gradient in the activity of a dissolved chemical species $x$ ionized to $x^{z}$ will give rise to an electromotive force (emf) over a material. If there is only one dominating ionic charge carrier and the sample is equipped with two equal and inert electrodes at the same absolute temperature $T$, and no external current is drawn, the measured voltage over the sample is ${ }^{36}$ :

$$
E_{\mathrm{II}-\mathrm{I}}=\frac{-k_{\mathrm{B}} T}{z e} \int_{\mathrm{I}}^{\mathrm{II}} t_{x^{\mathrm{z}}} d \ln a_{x}
$$

where $k_{\mathrm{B}}$ is the Boltzmann constant, $z$ the charge, $e$ the elementary charge, $a_{x}$ the activity of the

neutral species $x$, and $t_{x^{z}}$ is the transport number for the charged species $x^{z}$ defined as $t_{x^{z}}=\frac{\sigma_{x^{z}}}{\sigma_{\text {total }}}$, where $\sigma$ denotes conductivity.

When small activity gradients are used and a mean transport number can be assumed constant throughout the sample, Equation 1 can be integrated to give:

$$
E_{\mathrm{II}-\mathrm{I}}=t_{x^{z}} \frac{-k_{\mathrm{B}} T}{z e} \ln \left(\frac{a_{x}^{\mathrm{II}}}{a_{x}^{\mathrm{I}}}\right)
$$

If the activities of $x$ are known by controlling the atmospheres on both sides of the sample, the mean transport number can be calculated by the measured voltage $\left(E_{\mathrm{II}-\mathrm{I}}\right)$ across the sample. For evaluation of the protonic transport number and charge carrier mechanism for porous oxides under wet conditions, the chemical equilibrium between water and oxygen must be taken into consideration:

$$
2 \mathrm{H}_{2} \mathrm{O}=2 \mathrm{H}_{2}+\mathrm{O}_{2}
$$

By inserting various protonic species for $x$ in Equation 2, and using the equilibrium between water and oxygen (Equation 3) expressions for the emf in each case can be obtained. $\mathrm{For} \mathrm{H}^{+}, \mathrm{OH}^{-}$, $\mathrm{H}_{3} \mathrm{O}^{+}$and generally hydrated protons $\mathrm{H}_{2 m+1} \mathrm{O}_{m}^{+}$these are ${ }^{36-37}$ : 


$$
\begin{aligned}
& E_{\mathrm{II}-\mathrm{I}}=t_{\mathrm{H}^{+}} \frac{k_{\mathrm{B}} T}{4 e}\left[-2 \ln \left(\frac{P_{\mathrm{H}_{2} \mathrm{O}}^{\mathrm{II}}}{P_{\mathrm{H}_{2} \mathrm{O}}^{\mathrm{I}}}\right)+\ln \left(\frac{P_{\mathrm{O}_{2}}^{\mathrm{II}}}{P_{\mathrm{O}_{2}}^{\mathrm{I}}}\right)\right] \\
& E_{\mathrm{II}-\mathrm{I}}=t_{\mathrm{OH}^{-}} \frac{k_{\mathrm{B}} T}{4 e}\left[2 \ln \left(\frac{P_{\mathrm{H}_{2} \mathrm{O}}^{\mathrm{II}}}{P_{\mathrm{H}_{2} \mathrm{O}}^{\mathrm{I}}}\right)+\ln \left(\frac{P_{\mathrm{O}_{2}}^{\mathrm{II}}}{P_{\mathrm{O}_{2}}^{\mathrm{I}}}\right)\right] \\
& E_{\mathrm{II}-\mathrm{I}}=t_{\mathrm{H}_{3} \mathrm{O}^{+}} \frac{k_{\mathrm{B}} T}{4 e}\left[-6 \ln \left(\frac{P_{\mathrm{H}_{2} \mathrm{O}}^{\mathrm{II}}}{P_{\mathrm{H}_{2} \mathrm{O}}^{\mathrm{I}}}\right)+\ln \left(\frac{P_{\mathrm{O}_{2}}^{\mathrm{II}}}{P_{\mathrm{O}_{2}}^{\mathrm{I}}}\right)\right] \\
& E_{\mathrm{II}-\mathrm{I}}=t_{\mathrm{H}_{2 m+1} \mathrm{O}_{m}^{+}} \frac{k_{\mathrm{B}} T}{4 e}\left[-2(2 m+1) \ln \left(\frac{P_{\mathrm{H}_{2} \mathrm{O}}}{P_{\mathrm{H}_{2} \mathrm{O}}^{\mathrm{I}}}\right)+\ln \left(\frac{P_{\mathrm{O}_{2}}^{\mathrm{II}}}{P_{\mathrm{O}_{2}}^{\mathrm{I}}}\right)\right]
\end{aligned}
$$

By measuring under a water vapor gradient only (and no gradient in $p \mathrm{O}_{2}$ ), we see from Equations 4-7 that the measured emf and the sign of the voltage will be dependent on the protonic charge carrier. If the transport is dominated by $\mathrm{OH}^{-}$, the observed emf will have opposite sign compared to transport of protons or hydrated protons. If the transport is dominated by the vehicle mechanism of hydroxonium ions $\left(\mathrm{H}_{3} \mathrm{O}^{+}\right)$, the emf will be three times higher compared to transport dominated by Grotthuss mechanism. For hydrated protons in general, the measured voltage will be $2 m+1$ times higher for $m$ molecules constituting the vehicle transporting the proton. If combinations of protonic species dominate the transport, the obtained emf will take intermediate values.

\section{Experimental}

Powders of $8 \mathrm{~mol} \%$ yttria-stabilized zirconia (8YSZ, TOSOH Corporation, Japan) were cold pressed at $100 \mathrm{MPa}$ and sintered at $1100{ }^{\circ} \mathrm{C}$ for $2 \mathrm{~h}$ in ambient air to porous nanocrystalline pellets of approximately $20 \mathrm{~mm}$ diameter and $1 \mathrm{~mm}$ thickness. The ramp rate for heating and cooling was $300{ }^{\circ} \mathrm{C} \cdot \mathrm{h}^{-1}$. The relative density of the pellets was approximately $50 \%$ from the sample weight and geometry.

Phase purity and sample morphology of the pellets were analyzed by X-ray diffraction (XRD, Bruker D8 Discover, $\mathrm{Cu} \mathrm{K} \mathrm{K}_{\alpha}$, Bragg-Brentano) and scanning electron microscopy (SEM, Hitachi SU8200, operated with acceleration voltage of $5 \mathrm{kV}$ ). The BET surface analyses were made using nitrogen physisorption measurements at liquid nitrogen temperature in a relative range of pressure of 0-0.99 $\mathrm{p} \cdot \mathrm{p}_{0}{ }^{-1}$ (Belsorp-Mini instrument, Japan). The samples were outgassed under vacuum over night at $250{ }^{\circ} \mathrm{C}$ before BET measurements.

For the electrical conductivity measurements, circular Pt electrodes of diameter $10 \mathrm{~mm}$ were painted on both sides of one of the samples using Pt ink (Metalor UK, Pt ink number 6926) and annealed at $900{ }^{\circ} \mathrm{C}$ for $1 \mathrm{~h}$ in ambient air (heating and cooling rates of $300{ }^{\circ} \mathrm{C} \cdot \mathrm{h}^{-1}$ ).

For emf measurements, electrodes of $\mathrm{Ag}$ were deposited on another sample by electroless plating. ${ }^{43}$ Four aqueous baths were prepared using deionized (DI) water: a $\mathrm{SnCl}_{2}$ surface activation bath $\left(3 \mathrm{~g} \mathrm{~L}^{-1}\right.$ in $\left.\sim 0.04 \mathrm{M} \mathrm{HCl}\right)$; a $\mathrm{PdCl}_{2}$ catalyst bath $\left(5 \mathrm{~g} \mathrm{~L}^{-1}\right.$ in $\left.\sim 0.06 \mathrm{M} \mathrm{HCl}\right)$; a $\mathrm{Ag}$ 
bath (4.5 $\mathrm{g} \mathrm{AgNO}_{3}, 3.5 \mathrm{~mL}$ ammonia solution $\left(\mathrm{NH}_{4} \mathrm{OH}, 30 \mathrm{wt} \%\right), 55 \mathrm{~mL}$ DI water, plus a small amount of 3,5-diiodo-L-tyrosine as stabilizer); and a salt bath (16.0 g NaKC $\mathrm{H}_{4} \mathrm{O}_{6}, 1.1 \mathrm{~g} \mathrm{MgSO}$, $36.0 \mathrm{~mL}$ DI water). First, the sample was degreased for $5 \mathrm{~min}$ in isopropanol in an ultrasonic bath, and then rinsed for $30 \mathrm{~s}$ in DI water. Second, the sample was kept in the $\mathrm{SnCl}_{2}$ bath for $90 \mathrm{~s}$, and then rinsed for $30 \mathrm{~s}$ in DI water. Third, the sample was kept in the $\mathrm{PdCl}_{2}$ bath for $90 \mathrm{~s}$, and then rinsed for $30 \mathrm{~s}$ in DI water. Finally, the Ag bath and the salt bath were mixed and the sample was kept in the mixed bath for autocatalytic Ag plating at room temperature at $\mathrm{pH} \sim 11$ for $10 \mathrm{~min}$, and then rinsed for $30 \mathrm{~s}$ in DI water. After the deposition, the sample was sanded around the edge to define electrodes on top and bottom. Resistance measurements indicated no percolating network of plated silver through the sample.

All electrical measurements were carried out in a ProboStat measurement cell (NorECs, Norway). The cell was shielded using a steel outer tube functioning as a Faraday cage. The atmosphere was controlled using a gas mixer described in detail in Ref. ${ }^{36}$ The humidity was controlled by

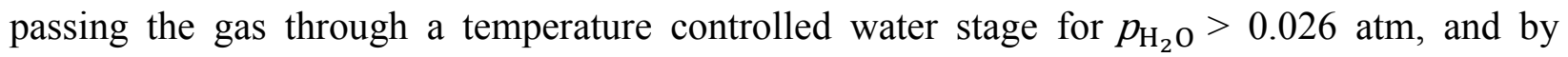
mixing bottle dry gas and gas passing through a saturated $\mathrm{KBr}$ solution at room temperature for $p_{\mathrm{H}_{2} \mathrm{O}}<0.026 \mathrm{~atm}$.

For the transport number measurements a high temperature silicone (Sika, Norway) was used for sealing between the inner alumina tube and the sample. The gas flow over the electrodes was kept high to ensure negligible contributions from diffusion through the porous sample. The voltage over the sample was recorded using a Keithley 6430 Sub-Femtoamp Remote Sourcemeter. In order to subtract any thermal and other offset contributions, the emf was recorded also under reversed gas conditions. The emf was measured under small water vapour gradients while maintaining a constant oxygen pressure of 0.05 atm on both sides of the cell. Due to large electrode resistances, the total DC resistance over the cell was very high. This complicates the measurement of small voltage differences over the cell due to parasitic current leakages from the high impedance terminal onto the faraday cage encapsulating the measurement cell. To minimize the effect of leakage currents, the faraday cage was kept at the same potential as the high-impedance terminal by connecting it to the driven shield of the voltmeter.

All AC conductivity impedance measurements were performed with a standard 2-electrode-4wire setup and connected to a Novocontrol alpha-A impedance spectrometer with a ZG4 interface. The impedance spectra were recorded within the frequency range from $10 \mathrm{MHz}$ to 1 $\mathrm{mHz}$ with an oscillation voltage of $0.1 \mathrm{~V}$ in dry or wet $\left(p_{\mathrm{H}_{2} \mathrm{O}}=0.026 \mathrm{~atm}\right.$ or $\left.p_{\mathrm{D}_{2} \mathrm{O}}=0.023 \mathrm{~atm}\right)$ Ar as a function of temperature $\left(25-400^{\circ} \mathrm{C}\right)$, in $\mathrm{N}_{2}$ at $\mathrm{RT}$ with varying $\mathrm{RH}(0.25-0.84)$, or in $\mathrm{O}_{2}$ as function of temperature $\left(25-100{ }^{\circ} \mathrm{C}\right)$ at fixed relative humidity $(0.20,0.45,0.60,0.70$, and 0.84). Specific conductivities for the porous material were calculated from electrode area and sample thickness, i.e., without correction for the porosity. 
Data were analysed and modelled using ZVIEW equivalent circuit fitting software (version 2.9, Scribner Associates Inc.). A parasitic parallel capacitance, $C_{\text {stray }}$, was assumed and included in the fitting, using the equivalent model in Figure 2, discussed in detail in Ref. ${ }^{39}$ Data collected in dry atmosphere were deconvoluted without the circuit elements related to surface transport. The data recorded under wet atmosphere were deconvoluted using the full model, in which parameters for resistance and capacitance of bulk and grain boundaries are kept fixed from the dry measurement. In the cases when $R_{\text {inter }}$ was too small to be observed and fitted, its associated capacitance of the grain boundaries $\left(C_{\mathrm{gb}}\right)$ under wet conditions was still allowed to take on a value and vary in order to obtain an acceptable fit.

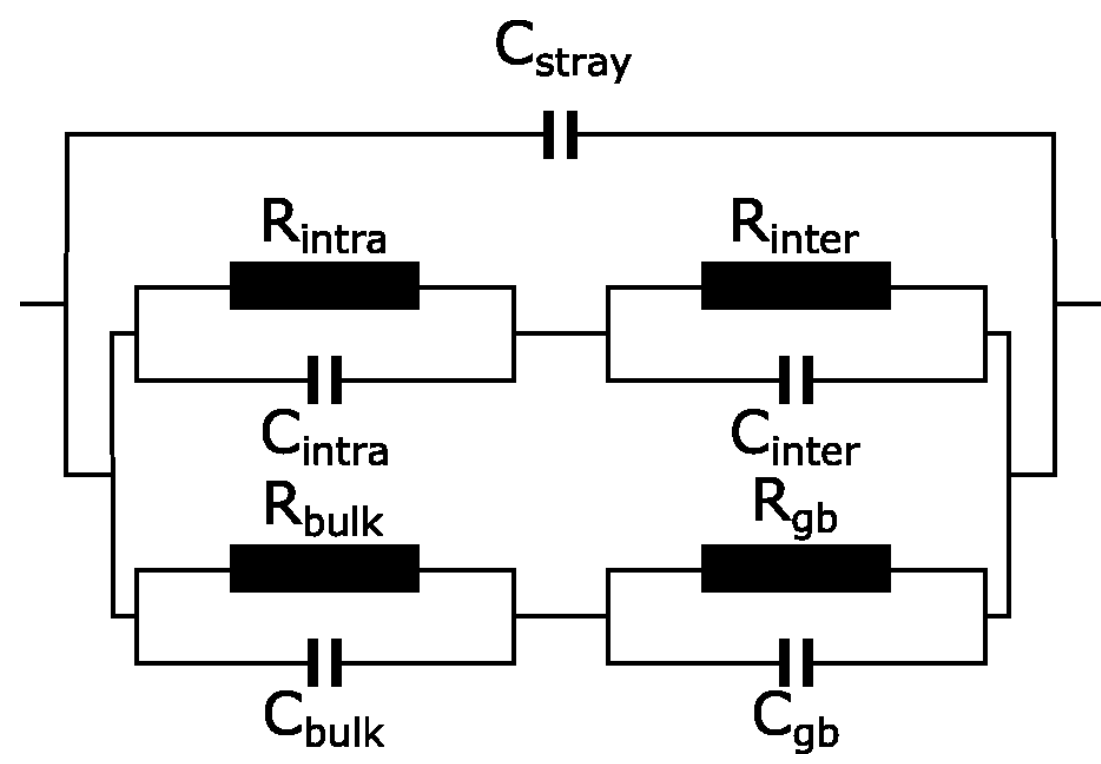

Figure 2. Equivalent circuit describing the ionic transport and associated capacitances in porous oxides, comprising volume transport in grain bulk and across grain boundaries (gb) and surface transport over grain surfaces (intra) and over grain boundary intersects (inter).

\section{Results}

The XRD analyses show that the samples are phase pure cubic 8YSZ. SEM images show that both samples have an open pore structure. The X-ray diffractogram of the sample used for the conductivity measurements and a typical SEM image of the samples are shown in Figure 3a and $\mathrm{b}$, respectively. The $\mathrm{N}_{2}$ adsorption isotherms and pore size distributions (BJH analyses) suggest that there will be marginal contributions from capillary condensation to the amount of water in the samples. 

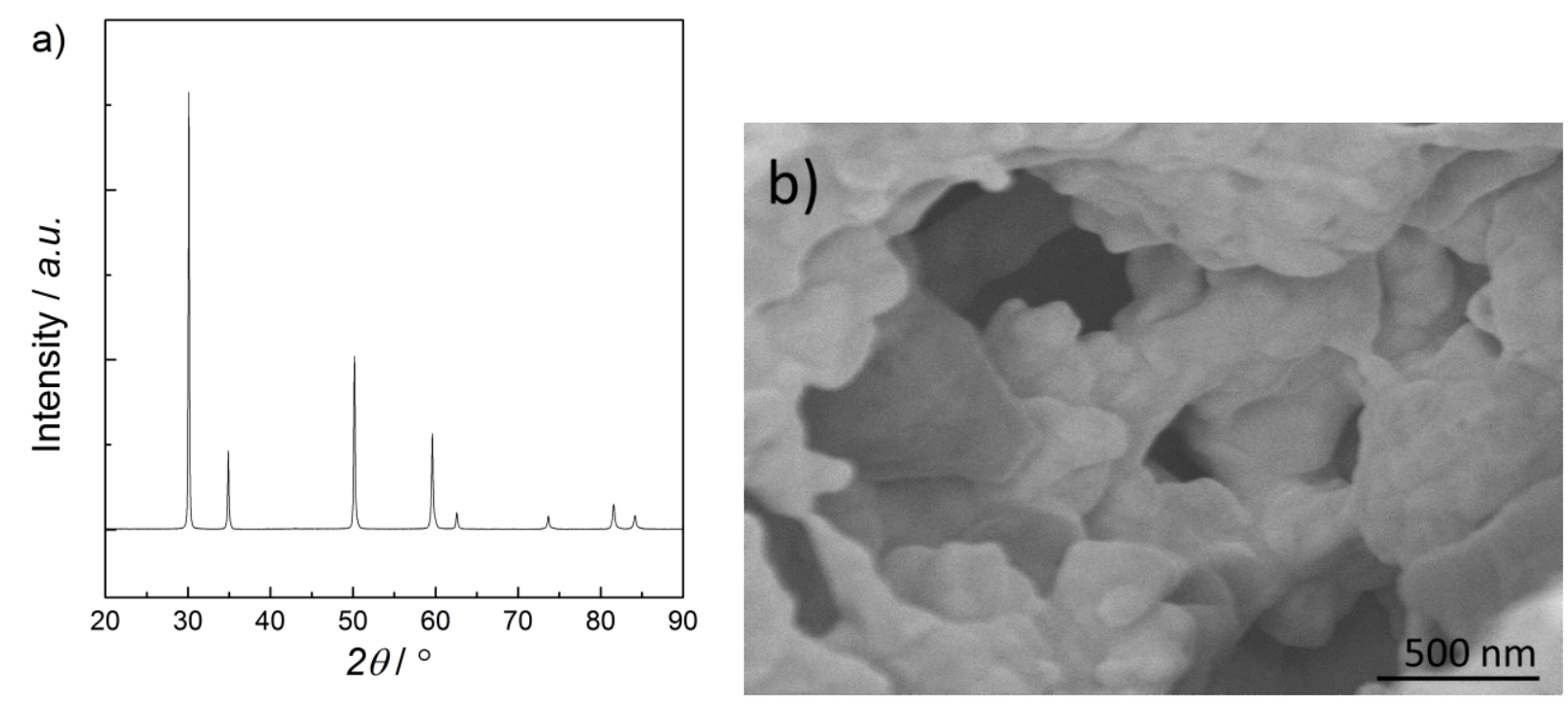

Figure 3 a) X-ray diffractograms and b) SEM image of the microstructure of 8YSZ sample sintered at $1100{ }^{\circ} \mathrm{C}$ for $2 \mathrm{~h}$.

Figure 4 shows apparent conductivities for solid volume (bulk and grain boundary) and protonic ( $\mathrm{H}$ and $\mathrm{D})$ surface transport, all using the same geometric specific factor, plotted versus the inverse absolute temperature. The volume conductivity under dry conditions follows Arrhenius behaviour, with activation energy of $1.05 \pm 0.02 \mathrm{eV}$. The conductivity in both $\mathrm{H}_{2} \mathrm{O}$ and $\mathrm{D}_{2} \mathrm{O}$ wetted atmosphere differs significantly from that in dry below $350{ }^{\circ} \mathrm{C}$, associated with protonic conduction within the chemisorbed and physisorbed water layers. The conductivity generally increases with increasing temperature above $\sim 175{ }^{\circ} \mathrm{C}$ where surface transport occurs predominantly in the chemisorbed water layer. The observed difference in conductivity between $\mathrm{H}_{2} \mathrm{O}$ and $\mathrm{D}_{2} \mathrm{O}$ wetted atmosphere is considerable and can only be explained by a free proton hopping transport mechanism. Below $\sim 150^{\circ} \mathrm{C}$ the conductivity in wet atmosphere increases with decreasing temperature and increasing $\mathrm{RH}$ due to enhanced amount of physisorbed water on the sample. All observations are thus in agreement with previous reports of conduction in porous YSZ. ${ }^{1-2,4-8}$ Moreover, the isotope effect decreases with decreasing temperature and indicates a change from Grotthuss mechanism to vehicle mechanism below $35{ }^{\circ} \mathrm{C}$. Below $31{ }^{\circ} \mathrm{C}$ the relative humidity exceeds $60 \%$, where the water layer shows more liquid-like behaviour. ${ }^{42}$ 


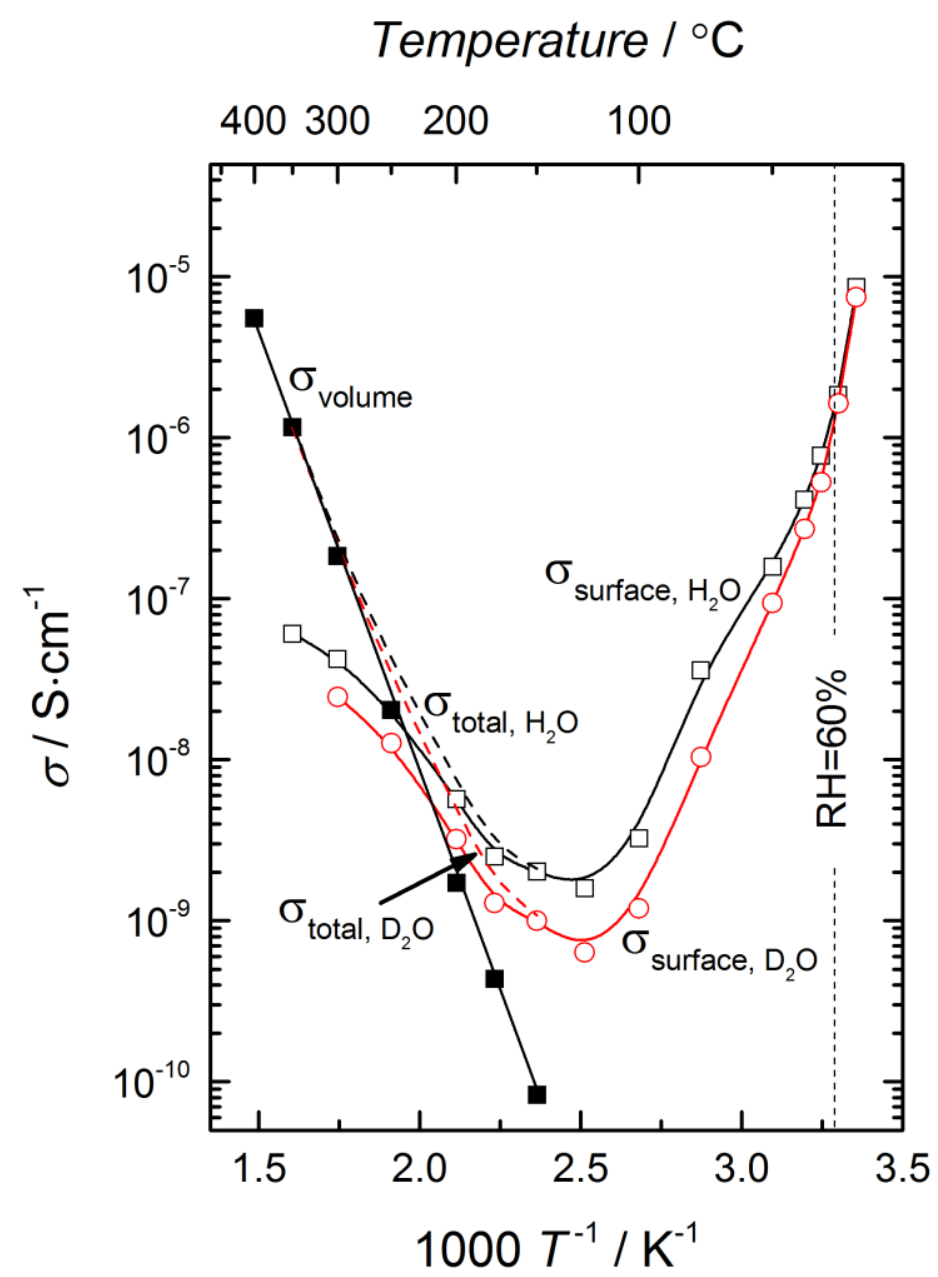

Figure 4. Apparent individual conductivity contributions for porous YSZ extracted from measurements in dry and wet $\left(\mathrm{H}_{2} \mathrm{O}\right.$ and $\left.\mathrm{D}_{2} \mathrm{O}\right)$ argon as function of inverse temperature at $p_{\mathrm{H}_{2} \mathrm{O}}=0.026 \mathrm{~atm}$ and $p_{\mathrm{D}_{2} \mathrm{O}}=0.023 \mathrm{~atm}$. Dashed parts of the graphs show the total conductivity under wet conditions. Solid lines are guides to the eye only.

Figure 5 displays the impedance spectra of the porous $8 \mathrm{YSZ}$ sample in wet $\left(\mathrm{H}_{2} \mathrm{O}\right.$ and $\left.\mathrm{D}_{2} \mathrm{O}\right) \mathrm{N}_{2}$ at $25^{\circ} \mathrm{C}$ for a) $25 \% \mathrm{RH}$ and b) $84 \% \mathrm{RH}$. They all show one somewhat depressed arc, which is attributed to the surface transport of water. As is seen, the isotope effect is strongly diminished at high relative humidity. 

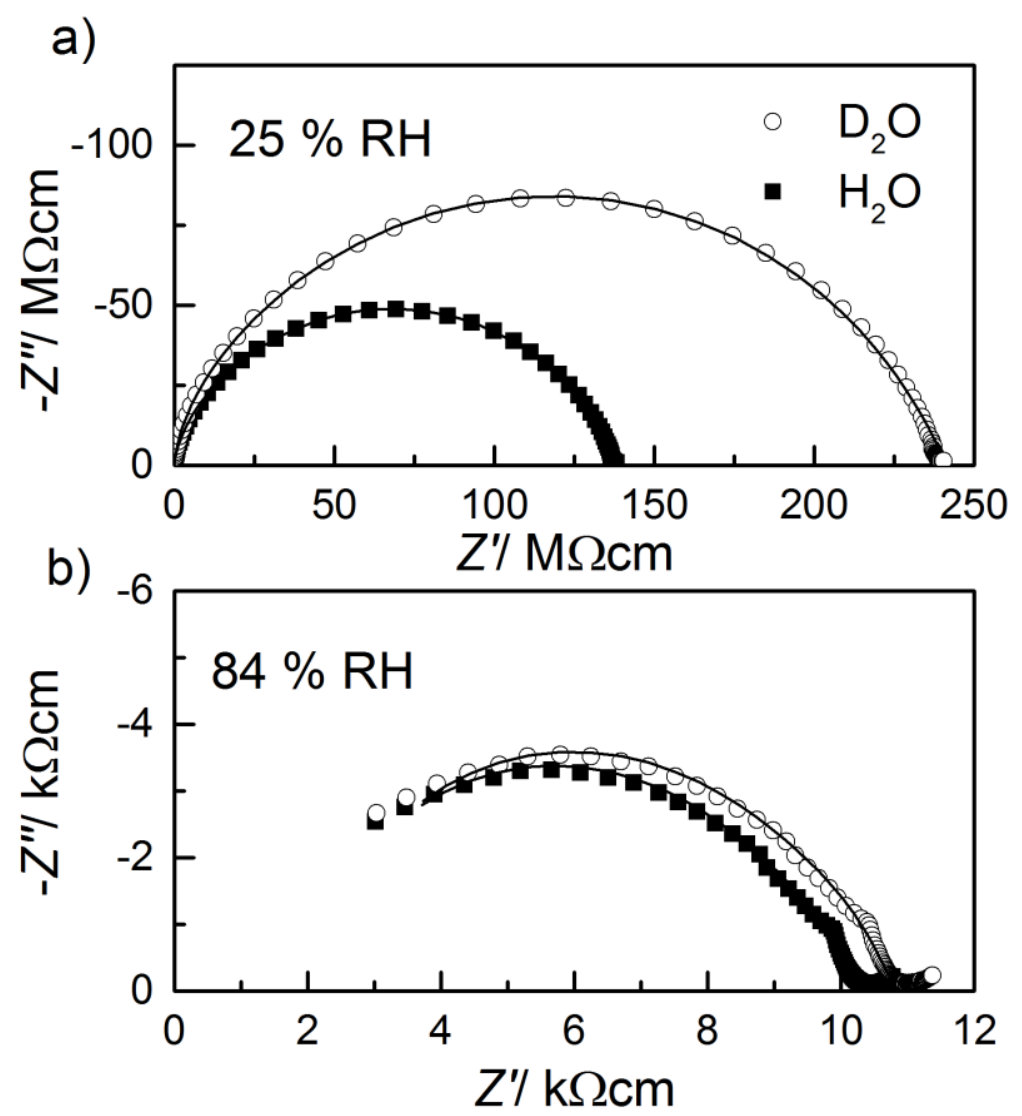

Figure 5. Nyquist plots of porous YSZ recorded under: a) $25 \% \mathrm{RH}$ and b) $84 \% \mathrm{RH}\left(\mathrm{H}_{2} \mathrm{O}\right.$ and $\left.\mathrm{D}_{2} \mathrm{O}\right)$ at $25{ }^{\circ} \mathrm{C}$.

Figure 6 shows the isothermal conductivity (lower part) and the isotope effect (upper part) of porous YSZ as function of RH in the range from 0.25 to 0.84 at RT. The conductivity increases drastically with increasing RH and water content, consistent with our previous results. ${ }^{31}$ The isotope effect decreases with increasing $\mathrm{RH}$ and water layer thickness, and levels out above $\sim 60 \%$ $\mathrm{RH}$. At low RH, the value of the isotope effect indicates a hopping based migration of protons (Grotthuss transport). Above $60 \% \mathrm{RH}$, the value of the isotope effect indicates a change to a vehicular mechanism for proton transport. The values at the lowest RH go beyond the classical value for the Grotthuss mechanism, similar to previously measured isotope effects for surface conduction on YSZ. ${ }^{8}$ It may be attributed to the slightly higher activation energy for deuterium diffusion as compared to proton diffusion, resulting from different zero-point energies, which is well-accepted and observed for bulk proton transport. ${ }^{44}$ 


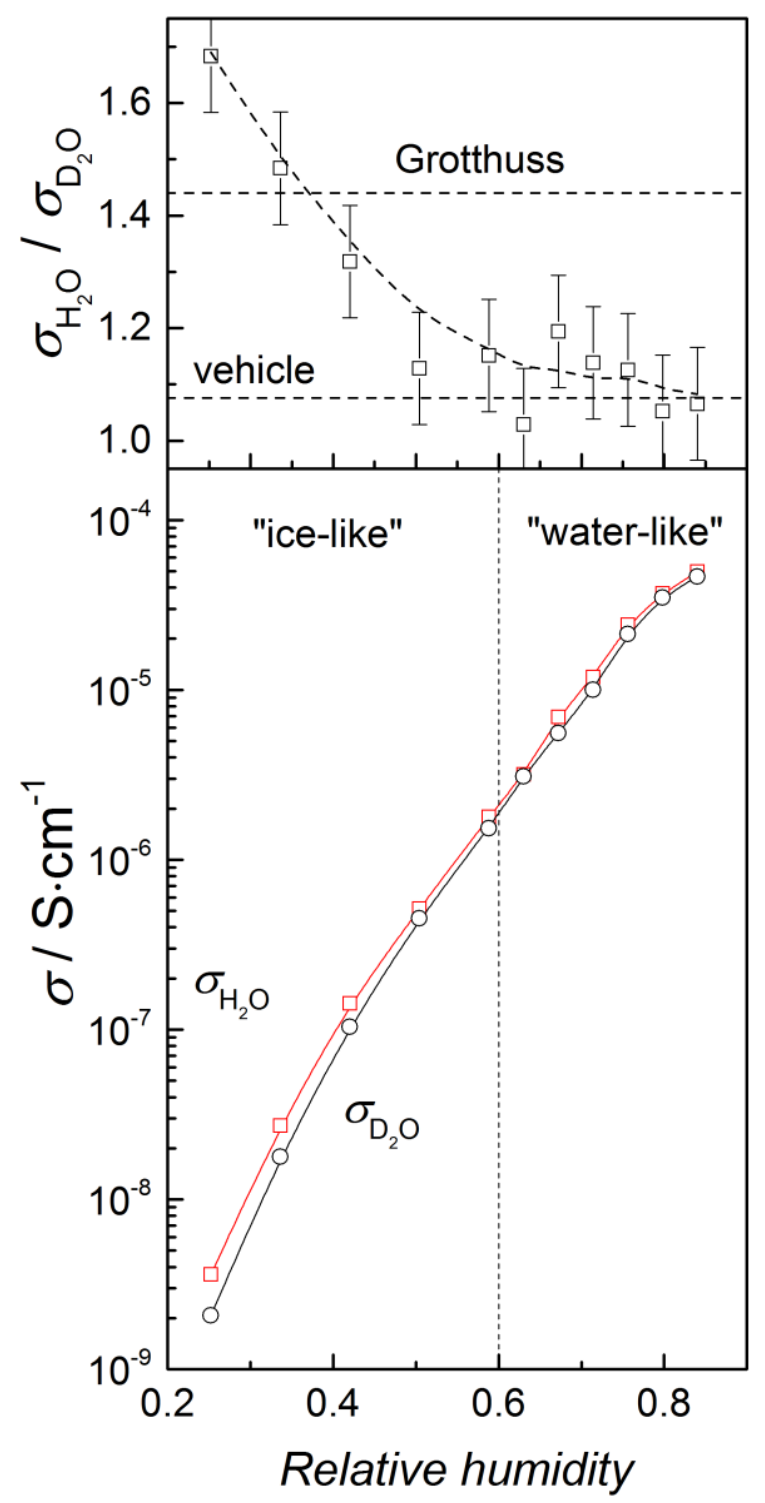

Figure 6. Isothermal conductivity (lower part) and isotope effect (upper part) of porous YSZ as a function of relative humidity $\left(\mathrm{H}_{2} \mathrm{O}\right.$ and $\left.\mathrm{D}_{2} \mathrm{O}\right)$ at $25^{\circ} \mathrm{C}$. All lines are guides to the eye only.

Figure 7 presents two representative emf measurements with $p_{\mathrm{H}_{2} \mathrm{O}}^{\mathrm{II}}=0.018$ atm (a) and $p_{\mathrm{H}_{2} \mathrm{O}}^{\mathrm{II}}=$ $0.024 \mathrm{~atm}(\mathrm{~b}) . p_{\mathrm{H}_{2} \mathrm{O}}^{\mathrm{I}}$ was kept constant at 0.026 atm in both cases. The atmospheres are reversed twice to enable correction for any thermal offset voltage over the sample. The dashed lines indicate the theoretical emf voltages for the cases $t_{\mathrm{H}^{+}}=1$ and $t_{\mathrm{H}_{3} \mathrm{O}^{+}}=1$. In the case of low $p_{\mathrm{H}_{2} \mathrm{O}}$ on the dry side (a), the measured emf is lower than the expected voltage for $t_{\mathrm{H}^{+}}=1$, whereas the emf exceeds this value when the dry side is more humidified (b), approaching the theoretical emf for $t_{\mathrm{H}_{3} \mathrm{O}^{+}}=1$, i.e., a hydroxonium conductor. We also note that the emf goes through a peak threshold - close to the expected emf for $t_{\mathrm{H}_{3} \mathrm{O}^{+}}=1$ before slowly decreasing towards its 
equilibrium value. If only one type of ionic species contributes to the total conductivity, the emf is considered a state function, and we should expect instantaneous equilibration of the voltage. However, if two or more types of ionic species are mobile, the emf is no longer a state function, and slow two-fold relaxation can be expected. Considering that oxide ion conductivity is extremely low under these conditions, the long equilibration times can only be explained by the contribution of two different protonic species, e.g., $\mathrm{H}^{+}$and $\mathrm{H}_{3} \mathrm{O}^{+}$, to the overall conductivity of the material under these intermediate humidity conditions.
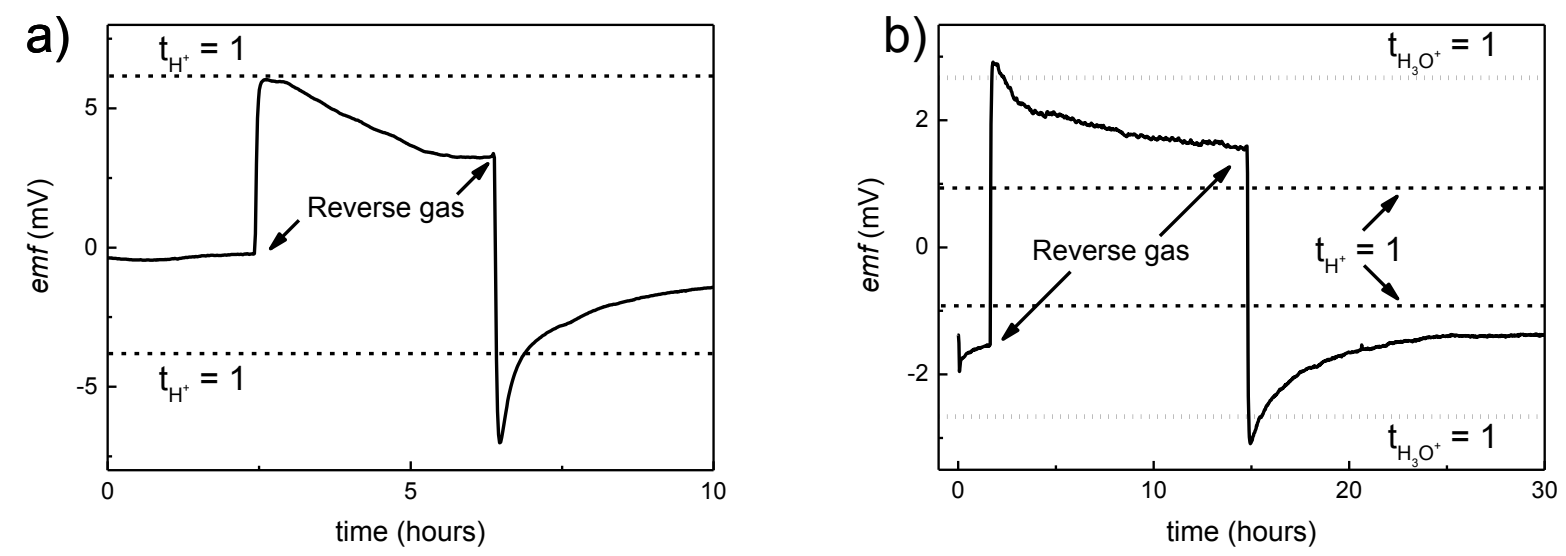

Figure 7. Emf voltage as a function of time for an emf measurement with $p_{\mathrm{H}_{2} \mathrm{O}}^{\mathrm{I}}=\mathbf{0 . 0 2 6}$ atm and $p_{\mathrm{H}_{2} \mathrm{O}}^{\mathrm{II}}=0.024 \mathrm{~atm}(\mathrm{a})$, and $p_{\mathrm{H}_{2} \mathrm{O}}^{\mathrm{II}}=\mathbf{0 . 0 1 8} \mathrm{atm}(\mathrm{b})$. The dashed lines show the levels of emf's corresponding to transport numbers of protons and hydroxonium ions equal to 1 .

The equilibrium emf response is recorded and used to calculate the apparent protonic transport number,

$$
t_{\mathrm{H}^{+} \text {apparent }}=\frac{e m f(\text { measured })}{e m f(\text { theoretical })}
$$

where emf (theoretical) corresponds to the theoretical emf value for $t_{\mathrm{H}^{+}}=1$, and the results - all taken with $p_{\mathrm{H}_{2} \mathrm{O}}^{\mathrm{I}}$ fixed at $0.026 \mathrm{~atm}$ - are plotted in Figure 8 as a function of the gradient applied. 


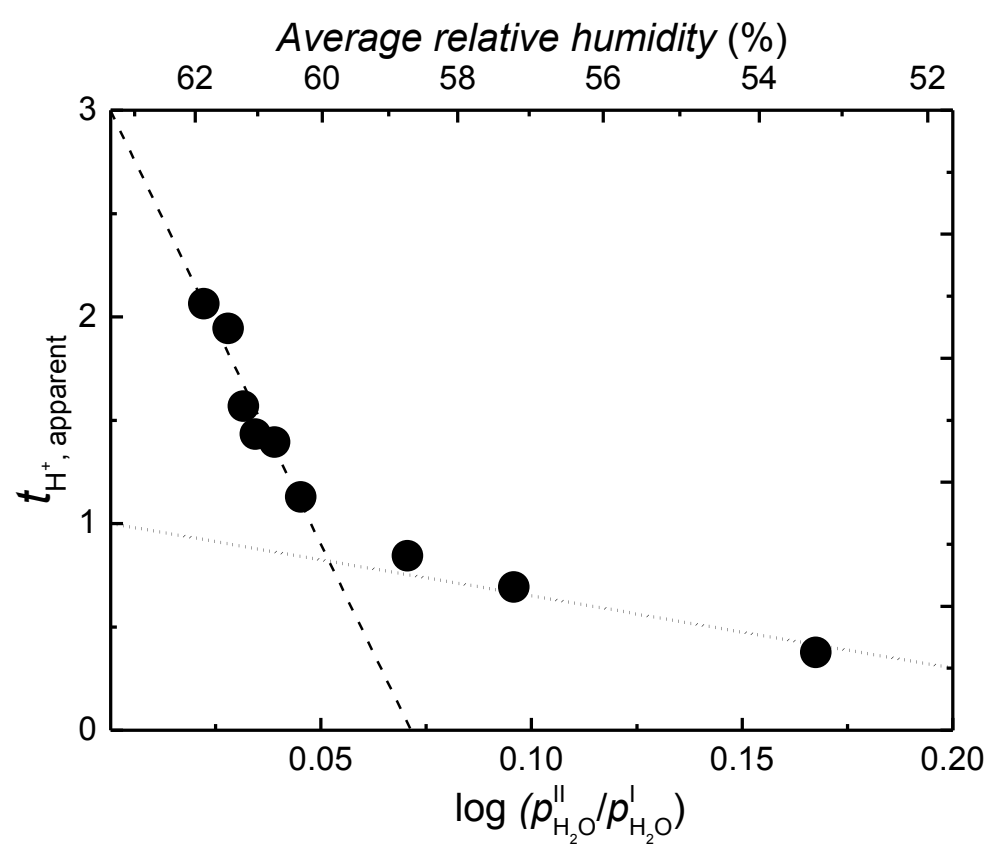

Figure 8. Apparent protonic transport number as function of water vapour gradient for porous YSZ measured at $30^{\circ} \mathrm{C}$. For all points, $p_{\mathrm{H}_{2} \mathrm{O}} \mathrm{I}$ is fixed at $0.026 \mathrm{~atm}$. The lines reflect linear regressions of two regions allowing extrapolation back to zero gradient.

It is immediately clear that the apparent transport number increases significantly as the gradient decreases and the average relative humidity exceed $60 \%$. We may also interpret the results to represent two different regions; one region under large gradient (and lower average $\mathrm{RH}$ ) where the extrapolated transport number for protons approaches unity $\left(t_{\mathrm{H}^{+}}=1\right)$, and one region at lower gradients (and high RH) where the apparent transport number approaches $3\left(t_{\mathrm{H}^{+}}=3\right.$ or $t_{\mathrm{H}_{3} \mathrm{O}^{+}}=1$ ) at zero gradient. These results indicate that protonic transport changes from a Grotthuss type mechanism at low relative humidity to vehicular hydroxonium transport at higher water content. The drag coefficient of water then equals 1 in Eq. 7. We also note that the slope of the curve changes approximately at $60 \% \mathrm{RH}$ where the upper part of the water layer structure changes from a rigid "ice-like" structure into a more loosely bound liquid structure, ${ }^{42}$ which corresponds well with observed change of isotope effect at the same water content (Figure 6).

Figure 9 shows the intra-grain conductivity of porous YSZ measured at fixed RH as a function of inverse temperature. The conductivity increases with increasing temperature and displays Arrhenius type behaviour for all humidity levels. The activation energies are determined by linear fitting of $\log \sigma T$ vs $1 / T$ and they decrease with decreasing RH. Similar results are observed for porous thin films of $\mathrm{SiO}_{2}$ and $\mathrm{TiO}_{2} .{ }^{3,21-22}$ 


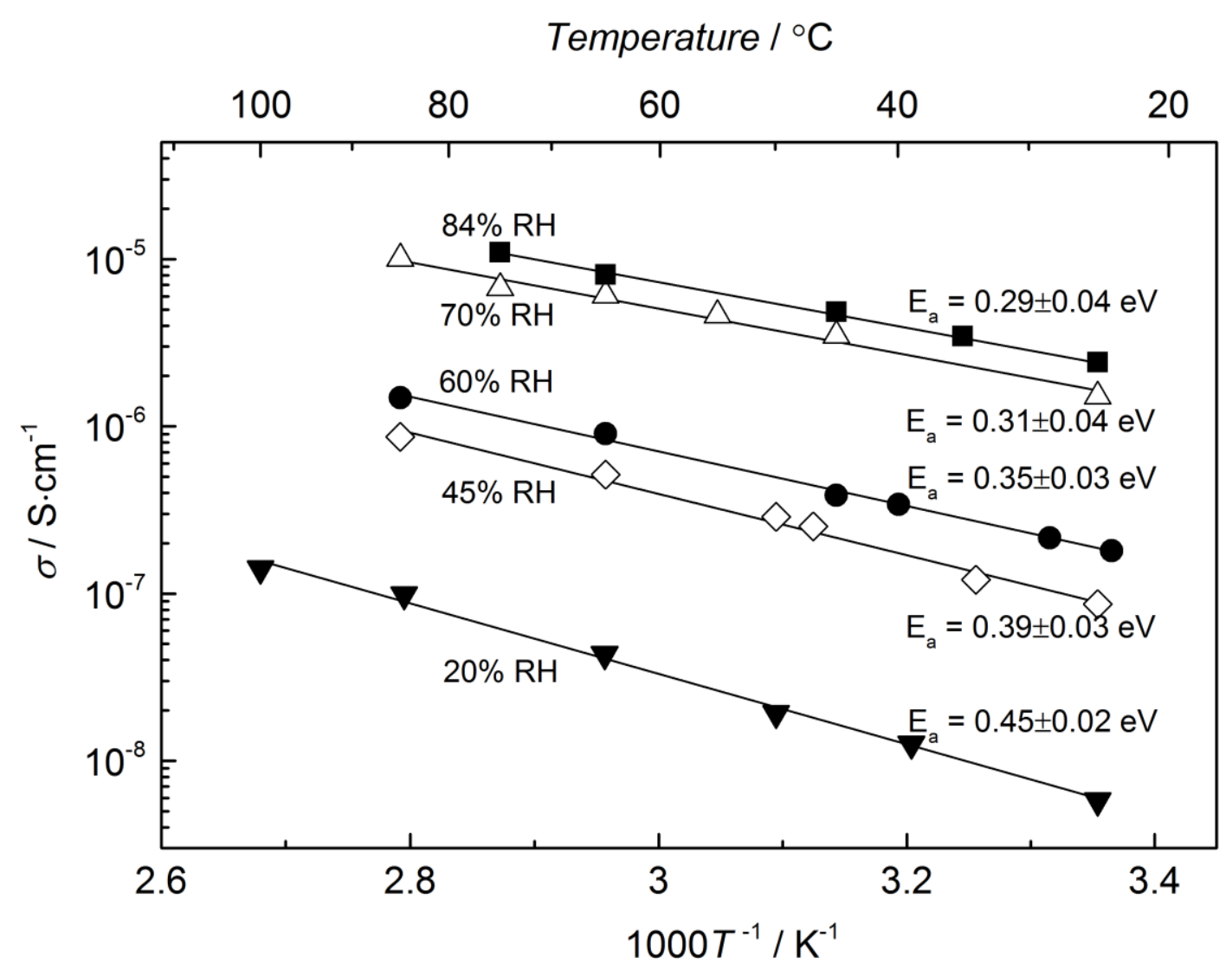

Figure 9. Intra-grain conductivity of porous $8 Y S Z$ under fixed relative humidity $(20 \%, 45 \%, 60 \%, 70 \%$ and $84 \%)$ as a function of inverse temperature.

According to adsorption theory (BET equation) the amount of adsorbed water on the oxide surface is determined by the activity of water $\left(p / p_{0}\right)$. Moreover, the protons in the physisorbed water layer are considered to be a product of the equilibrium reaction between adsorbed water and dominating acidic sites on the surface, ${ }^{16,30}$ which for $\mathrm{ZrO}_{2}$ is recently suggested to be: ${ }^{45}$

$$
\equiv \mathrm{ZrOH}_{2}+\mathrm{H}_{2} \mathrm{O} \text { (ads) } \rightleftarrows \equiv \mathrm{ZrOH}^{-}+\mathrm{H}_{3} \mathrm{O}^{+} \text {(ads) }
$$

The surface becomes negative ${ }^{46}$ compensated by hydroxonium in the water layer which constitutes the electrical double layer. The equilibrium constant $\left(K_{\mathrm{D}}\right)$ for the acid-base reaction can be expressed in terms of the activities of each participating species, in turn given as their concentrations divided by the standard concentration:

$$
K_{\mathrm{D}}=\frac{a_{\mathrm{H}_{3} \mathrm{O}^{+}} \cdot a_{\mathrm{ZrOH}^{-}}}{a_{\mathrm{H}_{2} \mathrm{O}} \cdot a_{\mathrm{ZrOH}_{2}}}=\frac{\frac{\left[\mathrm{H}_{3} \mathrm{O}^{+}\right]}{\left[\mathrm{H} 2 \mathrm{O}^{0}\right.} \cdot \frac{\left[\mathrm{ZrOH}^{-}\right]}{\left[\mathrm{ZrOH}_{2}\right]^{0}}}{\frac{\left[\mathrm{H}_{2} \mathrm{O}\right]}{[\mathrm{H} 2 \mathrm{O}]^{0}} \cdot \frac{\left[\mathrm{ZrOH}_{2}\right]}{\left[\mathrm{ZrOH}_{2}\right]^{0}}}=\frac{\left[\mathrm{H}_{3} \mathrm{O}^{+}\right] \cdot\left[\mathrm{ZrOH}^{-}\right]}{\left[\mathrm{H}_{2} \mathrm{O}\right] \cdot\left[\mathrm{ZrOH}_{2}\right]}
$$


Here, the concentrations can be expressed for instance as mol per surface area, and it may be noted that we use the same the standard concentration given by the $\mathrm{Zr}$ surface sites for both types of adsorbed species. The protons are considered to be the mobile charged species in the water layer ${ }^{47}$ such that the conduction is dominated by the protonic charge carrier. Moreover, the electroneutrality condition $\left[\mathrm{ZrOH}^{-}\right]=\left[\mathrm{H}_{3} \mathrm{O}^{+}\right]$has to be satisfied and the charge carrier concentration can be expressed in terms of mol per surface area:

$\left[\mathrm{H}_{3} \mathrm{O}^{+}\right]=\sqrt{\left[\mathrm{H}_{2} \mathrm{O}\right]\left[\mathrm{ZrOH}_{2}\right] K_{\mathrm{D}}}=\sqrt{\left[\mathrm{H}_{2} \mathrm{O}\right]\left[\mathrm{ZrOH}_{2}\right]} \cdot \exp \left(\frac{\Delta S_{\mathrm{D}}^{0}}{2 R}\right) \exp \left(\frac{-\Delta H_{\mathrm{D}}^{0}}{2 R T}\right)$

where $\Delta S_{\mathrm{D}}^{0}$ and $\Delta H_{\mathrm{D}}^{0}$ are the standard entropy and the enthalpy change for proton formation (Eq. 9). Assuming a dilute system, where the concentrations of protons and $\mathrm{ZrOH}^{-}$-defects remain small compared with the $\mathrm{ZrOH}_{2}$-sites, $\left[\mathrm{ZrOH}_{2}\right]$ can be replaced by $\left[\mathrm{ZrOH}_{2}\right]^{0}$. The concentration of water can further be expressed by the multilayer BET-equation, such that Eq. 11 becomes:

$$
\left[\mathrm{H}_{3} \mathrm{O}^{+}\right]=\sqrt{\frac{c\left(\frac{p}{p_{0}}\right) V_{\mathrm{m}}}{\left(1-\left(\frac{p}{p_{0}}\right)\right) \cdot\left(1+(c-1)\left(\frac{p}{p_{0}}\right)\right)}} \sqrt{\left[\mathrm{ZrOH}_{2}\right]^{0}} \cdot \exp \left(\frac{\Delta S_{\mathrm{D}}^{0}}{2 R}\right) \exp \left(\frac{-\Delta H_{\mathrm{D}}^{0}}{2 R T}\right)
$$

Here, $c$ is the BET constant. $v_{\mathrm{m}}$ expresses by tradition the "volume" of the monolayer, here defined in terms of mol per area. Moreover, if we multiply by the specific surface area $\left(S_{\mathrm{BET}}\right)$ and the gravimetric density of the sample $(\rho)$, the charge carrier concentration for a specific sample is expressed in terms of mol per volume sample. If we further assume an activated mobility:

$$
\mu=\mu_{0} \frac{1}{T} \exp \left(\frac{-\Delta H_{\mathrm{mob}}}{R T}\right)
$$

the full expression for the conductivity of the sample reads:

$$
\sigma_{p h}(T, p)=\sqrt{\frac{c\left(\frac{p}{p_{0}}\right) v_{m}}{\left(1-\left(\frac{p}{p_{0}}\right)\right) \cdot\left(1+(c-1)\left(\frac{p}{p_{0}}\right)\right)}} \sqrt{\left[\mathrm{ZrOH}_{2}\right]^{0}} \cdot S_{\mathrm{BET}} \rho F \exp \left(\frac{\Delta S_{\mathrm{D}}^{0}}{2 R}\right) \frac{\mu_{0}}{T} \exp \left(-\frac{\frac{1}{2} \Delta H_{\mathrm{D}}^{0}+H_{\mathrm{mob}}}{R T}\right)
$$

Here, $F$ denotes the Faraday constant. From the full expression for the protonic conductivity of the sample, the temperature dependency under fixed RH observed in Figure 9 can be ascribed to the enthalpies of defect formation $\left(\Delta H_{\mathrm{D}}^{0}\right)$ and mobility $\left(\Delta H_{\mathrm{mob}}\right)$ only. Thus, the observed decrease in activation energy with increasing relative humidity must have its origin from a reduction in the enthalpy of charge carrier formation, the enthalpy of the mobility, or both. 


\section{Low temperature proton conduction mechanism of porous oxides}

The conductivity measurements of porous YSZ as a function of temperature at fixed $p_{\mathrm{H}_{2} \mathrm{O}}$ and those as a function of relative humidity are in agreement with previous reports of protonic conductivity in porous YSZ. ${ }^{1-2,4-8,31,39}$ The charge carrier mechanism is studied by H/D-isotope analyses as function of temperature and relative humidity together with transport number measurements. Our wide temperature span and range of methodologies have enabled a more complete picture of the transport mechanism of surface protonic species in porous YSZ specifically, but should also be generally applicable for other porous oxides, especially those with an acidic surface termination.

At intermediate temperatures and wet conditions, protonic conduction primarily occurs within the hydrogen bonded layer. For porous $\mathrm{SiO}_{2}$ and $\mathrm{YSZ}$, vehicular transport of $\mathrm{H}_{3} \mathrm{O}^{+}$has been suggested as the dominating conducting species in the hydrogen bonded layer at low coverage, which changes to a predominantly Grotthuss type mechanism for continuous coverage at higher RH and/or lower temperature. ${ }^{16,30}$ However, recent results have suggested that Grotthuss-type structural diffusion dominates for the entire coverage range. ${ }^{8}$ Our (H/D) isotope study in the temperature range $150-300{ }^{\circ} \mathrm{C}$ support this, clearly indicating proton transport via Grotthuss-type migration both at low and continuous coverage of the hydrogen bonded layer above $150^{\circ} \mathrm{C}$.

At lower temperatures, where protonic transport in the physisorbed water layer dominates, $2,30,39$ the isotope effect indicates a free proton hopping transport mechanism above $30{ }^{\circ} \mathrm{C}$ and vehicular transport below. The relative humidity exceeds $60 \% \mathrm{RH}$ at $31{ }^{\circ} \mathrm{C}$, which agrees well with the observations from the transport number measurements performed at $30{ }^{\circ} \mathrm{C}$ and the isotope study at RT, showing that hydroxonium is the predominant charge carrier above $60 \% \mathrm{RH}$. In the study of nano-grained YSZ by S. Miyoshi et al., ${ }^{8}$ the transition between the Grotthuss and vehicle mechanism is observed around $50{ }^{\circ} \mathrm{C}$ (for $p_{\mathrm{H}_{2} \mathrm{O}}=0.023$ atm), rationalized by capillary condensation at that specific temperature resulting in a more liquid-like water layer. Our BET and $\mathrm{BJH}$ analyses indicate minor contribution of capillary condensation for our material, such that the transition into a more liquid-like water structure occurs at the temperature when the relative humidity exceeds $\sim 60 \% \mathrm{RH}^{42}$ Thus, the two studies agree that the conduction mechanism changes from Grotthuss to vehicle type mechanism when the water layer changes from "ice-like" to "liquid-like" in its properties.

The decrease in activation energy with increasing humidity is in agreement with previous results of the protonic surface conduction of $\mathrm{TiO}_{2}$ and $\mathrm{SiO}_{2}{ }^{3,}{ }^{32}$ When seen in conjunction with the large increase in conductivity with increasing relative humidity (Fig. 6), it is clear that the local chemical environment becomes increasingly favourable for protonic conduction in a water layer with increasing thickness. The observed change from $0.43 \mathrm{eV}$ at $20 \% \mathrm{RH}$ to $0.28 \mathrm{eV}$ at $84 \% \mathrm{RH}$ reflects a change in the conductivity of more than two orders of magnitude, which is part of the reason for the large increase in the conductivity as a function of RH as seen in Fig. 6. The 
amount of water is in the same interval increased just 2-3 times, verified by sorption measurements in previous work. ${ }^{31}$

Kreuer et $a l^{48}$ proposed long ago that the thermodynamics of charge carrier formation and mobility changes with increasing relative humidity due to dynamical disorder and decreasing binding energy to the surface. From ab initio molecular studies on $\mathrm{ZnO}$ surfaces it is found that the proton hopping barrier decreases from $0.16 \mathrm{eV}$ to $0.07 \mathrm{eV}$ from a monolayer to multilayer water structure due to increased flexibility of the water structure. ${ }^{47}$ Similar computational results are also reported for proton migration along other oxide surfaces. ${ }^{49-50}$ Moreover, the activation energy for Nafion is found to decrease from $0.24 \mathrm{eV}$ at $55 \% \mathrm{RH}$ to $0.17 \mathrm{eV}$ above $90 \% \mathrm{RH}$, attributed to an increased dissociation of the sulfonic acid at higher level of hydration. ${ }^{32,51}$ The observed change in the activation energy in this study is larger than the change in enthalpy of migration on $\mathrm{ZnO}$ and the change in activation energy in Nafion, supporting that our change in activation energy for YSZ may be related to changes in the enthalpy of both dissociation and mobility. Any further decoupling of the mobility and concentration contribution to the overall activation energy cannot be done on the basis of the present data set. The gradual decrease in activation energy observed in this work coincides with a change in transport mechanism from predominantly Grotthuss-type into vehicle type transport. Thus, we may speculate that a decreased binding energy to the surface at high relative humidity results in free and more mobile hydroxonium ions that move within the adsorbed water layer on the surface with lower migration barriers.

Porous nanocrystalline oxides show many similarities with polymeric proton conductors, where the conduction mechanism is broadly studied, and changes from Grotthuss at low RH to a vehicular mechanism at higher RH. ${ }^{51-52}$ Both materials act as an acidic host material for adsorbed water inside the material wherein protonic conduction can occur. Polymers are able to swell and keep the water inside, while porous nanocrystalline oxides on the contrary need high RH and small pore sizes, allowing pore condensation, to keep the water in the material. By transport number measurements, the average number of water molecules the proton is carrying in the vehicle ( $\mathrm{n}$ in Equation 7) is determined to be $2.65 \mathrm{H}_{2} \mathrm{O}$ in Nafion at full hydration. ${ }^{34,37-38}$ We may therefore expect that the drag coefficient also increases to values larger than unity for porous oxides at high relative humidity and thick water layers.

\section{Conclusions}

The electrical properties and the charge carrier mechanism of porous YSZ ceramic samples have been investigated over wide ranges of relative humidity and temperature. Humidity introduces protonic surface conduction, making porous YSZ a predominantly protonic conductor below $\sim 150^{\circ} \mathrm{C}$. In the chemisorbed water layer free protons migrate by the Grotthuss mechanism. By transport number measurements and isotope studies the transport mechanism in the physisorbed layer is shown to change to a vehicle mechanism around $60 \% \mathrm{RH}$, at the $\mathrm{RH}$ level where the 
adsorbed water layer is changing from an "ice-like" to a "water-like" structure. The activation energy of the protonic transport is shown to be dependent of the water layer thickness, caused by changes in the enthalpy changes probably of both migration and defect formation. The activation energies are found to be of similar magnitude for both Grotthuss and vehicular transport, showing that the transport mechanism cannot be evaluated solely on measured activation energies.

\section{Acknowledgments}

The authors are grateful to Dr. Per Martin Rørvik, Sintef, for the electroplating of electrodes. This work has received financial support by The Research Council of Norway through the RENERGI “NaProCs” \#216039 and ERA-NET New INDIGO "NANOMFC” \#237642 projects.

\section{References}

1. Kim, S.; Avila-Paredes, H. J.; Wang, S.; Chen, C.-T.; De Souza, R. A.; Martin, M.; Munir, Z. A., On the Conduction Pathway for Protons in Nanocrystalline Yttria-Stabilized Zirconia. Physical Chemistry Chemical Physics 2009, 11, 3035-3038.

2. $\quad$ Scherrer, B.; Schlupp, M. V. F.; Stender, D.; Martynczuk, J.; Grolig, J. G.; Ma, H.; Kocher, P.; Lippert, T.; Prestat, M.; Gauckler, L. J., On Proton Conductivity in Porous and Dense Yttria Stabilized Zirconia at Low Temperature. Advanced Functional Materials 2013, 23, 1957-1964.

3. Colomer, M. T., Nanoporous Anatase Thin Films as Fast Proton-Conducting Materials. Advanced Materials 2006, 18, 371-374.

4. $\quad$ Avila-Paredes, H. J.; Zhao, J.; Wang, S.; Pietrowski, M.; De Souza, R. A.; Reinholdt, A.; Munir, Z. A.; Martin, M.; Kim, S., Protonic Conductivity of Nano-Structured Yttria-Stabilized Zirconia: Dependence on Grain Size. Journal of Materials Chemistry 2010, 20, 990-994.

5. Hinterberg, J.; Adams, A.; Blumich, B.; Heitjans, P.; Kim, S.; Munir, Z. A.; Martin, M., 1h-Nmr Measurements of Proton Mobility in Nano-Crystalline Ysz. Physical Chemistry Chemical Physics 2013, 15, 19825-19830.

6. Kim, S.; Anselmi-Tamburini, U.; Park, H. J.; Martin, M.; Munir, Z. A., Unprecedented Room-Temperature Electrical Power Generation Using Nanoscale Fluorite-Structured Oxide Electrolytes. Advanced Materials 2008, 20, 556-559.

7. Miyoshi, S.; Akao, Y.; Kuwata, N.; Kawamura, J.; Oyama, Y.; Yagi, T.; Yamaguchi, S., Water Uptake and Conduction Property of Nano-Grained Yttria-Doped Zirconia Fabricated by Ultra-High Pressure Compaction at Room Temperature. Solid State Ionics 2012, 207, 21-28.

8. Miyoshi, S.; Akao, Y.; Kuwata, N.; Kawamura, J.; Oyama, Y.; Yagi, T.; Yamaguchi, S., Low-Temperature Protonic Conduction Based on Surface Protonics: An Example of Nanostructured Yttria-Doped Zirconia. Chemistry of Materials 2014, 26, 5194-5200.

9. Pérez-Coll, D; Mather, G. C., Electrical Transport at Low Temperatures in Dense Nanocrystalline Gd-Doped Ceria. Solid State Ionics 2010, 181, 20-26.

10. Avila-Paredes, H. J.; Chen, C.-T.; Wang, S.; De Souza, R. A.; Martin, M.; Munir, Z.; Kim, S., Grain Boundaries in Dense Nanocrystalline Ceria Ceramics: Exclusive Pathways for Proton Conduction at Room Temperature. Journal of Materials Chemistry 2010, 20, 1011010112. 
11. Gregori, G.; Shirpour, M.; Maier, J., Proton Conduction in Dense and Porous Nanocrystalline Ceria Thin Films. Advanced Functional Materials 2013, 23, 5861-5867.

12. Shirpour, M.; Gregori, G.; Merkle, R.; Maier, J., On the Proton Conductivity in Pure and Gadolinium Doped Nanocrystalline Cerium Oxide. Physical Chemistry Chemical Physics 2011, 13, 937-940.

13. Takamura, H.; Takahashi, N., Electrical Conductivity of Dense Nanocrystalline Ceria under Humidified Atmosphere. Solid State Ionics 2010, 181, 100-103.

14. Maglia, F.; Tredici, I. G.; Spinolo, G.; Anselmi-Tamburini, U., Low Temperature Proton Conduction in Bulk Nanometric Tio2 Prepared by High-Pressure Field Assisted Sintering. Journal of Materials Research 2012, 27, 1975-1981.

15. Tredici, I. G.; Maglia, F.; Ferrara, C.; Mustarelli, P.; Anselmi-Tamburini, U., Mechanism of Low-Temperature Protonic Conductivity in Bulk, High-Density, Nanometric Titanium Oxide. Advanced Functional Materials 2014, 24, 5137-5146.

16. Anderson, J. H.; Parks, G. A., Electrical Conductivity of Silica Gel in the Presence of Adsorbed Water. The Journal of Physical Chemistry 1968, 72, 3662-3668.

17. Nogami, M.; Abe, Y., Evidence of Water-Cooperative Proton Conduction in Silica Glasses. Physical Review B 1997, 55, 12108-12112.

18. Nogami, M.; Nagao, R.; Makita, K.; Abe, Y., Fast Proton-Conducting P2o5-Zro2-Sio2 Glasses. Applied Physics Letters 1997, 71, 1323-1325.

19. Nogami, M.; Nagao, R.; Wong, C., Proton Conduction in Porous Silica Glasses with High Water Content. The Journal of Physical Chemistry B 1998, 102, 5772-5775.

20. Nogami, M.; Nagao, R.; Wong, C.; Kasuga, T.; Hayakawa, T., High Proton Conductivity in Porous P2o5-Sio2 Glasses. The Journal of Physical Chemistry B 1999, 103, 9468-9472.

21. Fujita, S.; Koiwai, A.; Kawasumi, M.; Inagaki, S., Enhancement of Proton Transport by High Densification of Sulfonic Acid Groups in Highly Ordered Mesoporous Silica. Chemistry of Materials 2013, 25, 1584-1591.

22. Colomer, M. T.; Rubio, F.; Jurado, J. R., Transport Properties of Fast Proton Conducting Mesoporous Silica Xerogels. Journal of Power Sources 2007, 167, 53-57.

23. Kim, H.; Prakash, S.; Mustain, W. E.; Kohl, P. A., Sol-Gel Based Sulfonic AcidFunctionalized Silica Proton Conductive Membrane. Journal of Power Sources 2009, 193, 562569.

24. Jiang, S. P., Functionalized Mesoporous Structured Inorganic Materials as High Temperature Proton Exchange Membranes for Fuel Cells. Journal of Materials Chemistry A 2014, 2, 7637-7655.

25. Vaivars, G.; Kleperis, J.; Lusis, A., Antimonic Acid Hydrate Xerogels as Proton Electrolytes. Solid State Ionics 1993, 61, 317-321.

26. Knudsen, N.; Krogh Andersen, E.; Krogh Andersen, I. G.; Norby, P.; Skou, E., TinZeolites, Syntheses and Ionic Conductivity. Solid State Ionics 1993, 61, 153-161.

27. Feng, S.; Greenblatt, M., Proton Conductivity and Humidity-Sensing Properties at High Temperature of the Nasicon-Based Composite Material Hydrogen Zirconium PhosphateZirconium Pyrophosphate Ceramic (Hzr2p3o12.Zrp2o7). Chemistry of Materials 1993, 5, 12771282.

28. Farahani, H.; Wagiran, R.; Hamidon, M., Humidity Sensors Principle, Mechanism, and Fabrication Technologies: A Comprehensive Review. Sensors 2014, 14, 7881.

29. Traversa, E., Ceramic Sensors for Humidity Detection: The State-of-the-Art and Future Developments. Sensors and Actuators B: Chemical 1995, 23, 135-156. 
30. Raz, S.; Sasaki, K.; Maier, J.; Riess, I., Characterization of Adsorbed Water Layers on Y2o3-Doped Zro2. Solid State Ionics 2001, 143, 181-204.

31. Stub, S.; Vøllestad, E.; Norby, T., Protonic Surface Conduction Controlled by Space Charge of Intersecting Grain Boundaries in Porous Ceramics. Submitted 2017.

32. Kreuer, K.-D.; Paddison, S. J.; Spohr, E.; Schuster, M., Transport in Proton Conductors for Fuel-Cell Applications: Simulations, Elementary Reactions, and Phenomenology. Chemical Reviews 2004, 104, 4637-4678.

33. Kreuer, K.-D., Proton Conductivity: Materials and Applications. Chemistry of Materials 1996, 8, 610-641.

34. Ise, M.; Kreuer, K. D.; Maier, J., Electroosmotic Drag in Polymer Electrolyte Membranes: An Electrophoretic Nmr Study. Solid State Ionics 1999, 125, 213-223.

35. Dippel, T.; Kreuer, K. D., Proton Transport Mechanism in Concentrated Aqueous Solutions and Solid Hydrates of Acids. Solid State Ionics 1991, 46, 3-9.

36. Norby, T., Emf Method Determination of Conductivity Contributions from Protons and Other Foreign Ions in Oxides. Solid State Ionics 1988, 28, 1586-1591.

37. Jak, M. J. G.; Raz, S.; van Rij, L. N.; Schoonman, J.; Riess, I., Voltage-Concentration Relations with Enhanced Slopes in Electrochemical Cells Based on Nafion ${ }^{\circledR}$. Solid State Ionics 2001, 143, 205-217.

38. Xie, G.; Okada, T., Water Transport Behavior in Nafion 117 Membranes. Journal of The Electrochemical Society 1995, 142, 3057-3062.

39. Stub, S.; Vøllestad, E.; Rørvik, P. M.; Norby, T., On the Interaction of Grain Boundaries and Protonic Surface Transport in Porous Oxides. Submitted 2017.

40. Langmuir, I., The Constitution and Fundamental Properties of Solids and Liquids. Part I. Solids. Journal of the American Chemical Society 1916, 38, 2221-2295.

41. Brunauer, S.; Emmett, P. H.; Teller, E., Adsorption of Gases in Multimolecular Layers. Journal of the American Chemical Society 1938, 60, 309-319.

42. Asay, D. B.; Kim, S. H., Evolution of the Adsorbed Water Layer Structure on Silicon Oxide at Room Temperature. The Journal of Physical Chemistry B 2005, 109, 16760-16763.

43. Paunovic, E. M. S. a. M., Electroless and Electrodeposition of Silver, in Modern Electroplating, 5th Edition; John Wiley \& Sons, 2010.

44. Nowick, A. S.; Vaysleyb, A. V., Isotope Effect and Proton Hopping in High-Temperature Protonic Conductors. Solid State Ionics 1997, 97, 17-26.

45. Sato, R.; Ohkuma, S.; Shibuta, Y.; Shimojo, F.; Yamaguchi, S., Proton Migration on Hydrated Surface of Cubic Zro2: Ab Initio Molecular Dynamics Simulation. The Journal of Physical Chemistry C 2015, 119, 28925-28933.

46. Ramanathan, S.; Kumar, K. P. K.; De, P. K.; Banerjee, S., Role of Dispersion Conditions on Grindability of Yttria Stabilized Zirconia (Ysz) Powders. Bull Mater Sci 2005, 28, 109-114.

47. Tocci, G.; Michaelides, A., Solvent-Induced Proton Hopping at a Water-Oxide Interface. The Journal of Physical Chemistry Letters 2014, 5, 474-480.

48. Kreuer, K. D.; Weppner, W.; Rabenau, A., Proton Conduction in Zeolites. Materials Research Bulletin 1982, 17, 501-509.

49. Předota, M.; Bandura, A. V.; Cummings, P. T.; Kubicki, J. D.; Wesolowski, D. J.; Chialvo, A. A.; Machesky, M. L., Electric Double Layer at the Rutile (110) Surface. 1. Structure of Surfaces and Interfacial Water from Molecular Dynamics by Use of Ab Initio Potentials. The Journal of Physical Chemistry B 2004, 108, 12049-12060. 
50. Kerisit, S.; Liu, C., Molecular Simulations of Water and Ion Diffusion in Nanosized Mineral Fractures. Environmental Science \& Technology 2009, 43, 777-782.

51. Kreuer, K. D., On the Development of Proton Conducting Materials for Technological Applications. Solid State Ionics 1997, 97, 1-15.

52. Ye, G.; Hayden, C. A.; Goward, G. R., Proton Dynamics of Nafion and Nafion/Sio2 Composites by Solid State Nmr and Pulse Field Gradient Nmr. Macromolecules 2007, 40, 15291537. 